\title{
Overview of Extension Program Planning Models ${ }^{1}$
}

\author{
John Diaz, Cody Gusto, and David Diehl²
}

\section{Abstract}

The purpose of this article is to articulate a comparative overview of the various program planning models designed and employed by Extension professionals in educational contexts. The use of program plan development models within Extension has a long history of application based upon environmental context, interest, and perceived value. Literature in the Extension field has featured numerous advocates offering detailed justifications for the employment of these models in Extension work. Utilizing a program planning model produces the most efficient return on investment of public funds for accountability purposes, encourages greater efficiency in providing solutions to client problems, improves general program accountability, and allows Extension personnel a greater range for flexibility and adaptability. Despite differences in format and emphasis between development models, each model demonstrates the foundational benefits derived from one of the most widely referenced program planning frameworks. While many Extension personnel may blend multiple development models to fit their context, interest, and values, each model provided will feature a needs assessment, program design and implementation, and program evaluation components within the operational context of that program.

\section{Introduction: Benefits of Program Planning Models \& A Widely Used Framework}

The purpose of this article is to articulate a comparative overview of the various program planning models designed and employed by Extension professionals in educational contexts. Program plan development is defined as "a continuous series of complex, interrelated processes which result in the accomplishment of the educational mission and objectives of the organization" (Seevers \& Graham, 2012). The use of program plan development models within Extension has a long history of application based upon environmental context, interest and perceived value (Franz, Garst \& Gagnon, 2015). Literature in the Extension field has featured numerous advocates offering detailed justifications for the employment of these models in Extension work. Forest, McKenna, and Donovan (1986) contend that utilizing a program planning model produces the most efficient return on investment of public funds for accountability purposes, encourages greater efficiency in providing solutions to client problems, improves general program accountability, and allows Extension personnel a greater range for flexibility and adaptability. According to Franz, Garst, and Gagnon (2015), the most complete justification for applying a development model comes from Duttweiler, with his view that planning models cultivate a host of benefits for Extension professionals, among them:

1. This document is AEC627, one of a series of the Department of Agricultural Education and Communication, UF/IFAS Extension. Original publication date January 2018. Visit the EDIS website at http://edis.ifas.ufl.edu.

2. John Diaz, assistant professor and Extension specialist, Department of Agricultural Education and Communication; Cody Gusto, graduate student, Department of Agricultural Education and Communication; and David Diehl, associate professor, Department of Family, Youth and Community Sciences; UF/IFAS Extension, Gainesville, FL 32611.

The Institute of Food and Agricultural Sciences (IFAS) is an Equal Opportunity Institution authorized to provide research, educational information and other services only to individuals and institutions that function with non-discrimination with respect to race, creed, color, religion, age, disability, sex, sexual orientation, marital status, national origin, political opinions or affiliations. For more information on obtaining other UF/IFAS Extension publications, contact your county's UF/IFAS Extension office. 
- a higher rate of outcome achievement

- a greater focus on intended outcomes

- a stable framework for resource planning/management

- parameters for documenting the process for accountability purposes

- an avenue for reflection and assessment for organizational growth

- context for diagnosing both a program's shortcomings and successes

- a basis for the reconciliation of program expectations

- a deliverable product by which Extension professionals may communicate impact to key stakeholders (Duttweiler, 2012)

Despite differences in format and emphasis between development models, each model demonstrates the foundational benefits derived from one of the most widely referenced program planning frameworks refined and popularized by Seevers and Graham (2012). The fundamental components proposed here include planning, design \& implementation, evaluation informed by organizational context, and a participant-driven needs assessment. The following section will provide a comparative overview of program development models for use by Extension professionals. While many Extension personnel may blend multiple development models to fit their context, interest, and values (Franz et al., 2015), each model provided will feature a needs assessment, program design and implementation, and program evaluation components within the operational context of that program (Boone et al., 2002).

\section{An Overview of Different Models}

Boone, Safrit, and Jones (2002) articulated a comprehensive review of major programming models in adult education that will serve as the basis for reference for several of the models discussed in summary below. Additional references include the TOP model (Rockwell \& Bennet, 1995) and the PRECEDE-PROCEED model (Green \& Kreuter, 2005). These models have been selected for their relevancy and application to the operational contexts of Extension programming. Each will be discussed in summary, followed by a comparative table identifying each model's operational context, system for client engagement, scope/focus, and guiding themes.

\section{Tyler (1949)}

Tyler's Basic Principles of Curriculum and Instruction (1949) posited a planning process organized around four main questions:
1. What educational purposes should the school seek to attain? (Defining appropriate learning objectives.)

2. How can learning experiences be selected which are likely to be useful in attaining these objectives? (Introducing useful learning experiences.)

3. How can learning experiences be organized for effective instruction? (Organizing experiences to maximize their effect.)

4. How can the development of learning experiences be evaluated? (Evaluating the process and revising the areas that were not effective.)

The model here focuses primarily on desired and achievable results for curriculum and instruction in formal education settings, which, as Boone et al. (2002) note, is fairly malleable and can be adapted to broader educational frameworks. He provides staged suggestions to address each of the four questions of interest, each thematically oriented around interlacing curriculum development to expected learning outcomes for students. As the curriculum is enacted, Tyler proposes teachers and program implementers take a constant, active role in determining whether or not their curricular hypotheses are in fact demonstrated by student behavior.

\section{Lippitt, Watson, \& Westley (1958)}

In Dynamics of Planned Change (1958), Lippitt, Watson, \& Westley provide a broader and perhaps less formally structured conception of planned change directed by the five main stages they articulate in their model:

\section{Developing awareness of the need for change}

\section{Establishing a "change relationship" with the planned change target}

\section{Working to implement change}

\section{Stabilizing/maintaining that change effect}

\section{Drawing towards a "terminal relationship" between the "change agent", the client, and the system at large.}

Boone et al. (2002) note that between each of these main stages, subheadings clarify the action-relationships between client and change agent where information exchange is frequent, program terms are tested and reevaluated, new behaviors are assessed, and support is actively sought from external sources. 


\section{Beal, Blunt, Powers, \& Johnson (1966)}

Social Action and Interaction presented an analysis of a staged process of program planning with an emphasis on social action - the process of acting as part of an organized group or community to create collective positive change. The planning model operates within a few different scales, addressing broad-scale social systems before homing in on context-specific problem analysis, triggering a stream of action sequences flowing outward from the original goal setting/planning stage of the program. Each of the 32 total stages are tied to a specific planning or evaluation action that is suited to the operational contexts of social action/ community organizing that some Extension programmers may highly value. Therefore, the model maintains a strong social-system orientation and advocates for a dynamic method of social action that is analytic, systematic, and seeks a judiciously crafted consensus for action (Boone et al., 2002).

\section{Boyle (1981)}

Employing a "lifelong learning" perspective, Boyle (1981) suggested there are developmental, institutional, and informational programs with variable goals, sources of objectives, use of knowledge, involvement of the learner, roles of the programmer, and standards of effectiveness (Franz et al., 2015). He suggested the following steps for programming, crafting a framework to intimately link programming to a participant-oriented "opportunity structure" for those continuing their education long after the program's treatment:

\section{Establish a philosophical basis for programming}

\section{Analyze problems and needs or concerns of people and} communities

\section{Involve potential clientele}

\section{Determine intellectual and social development levels}

5. Select sources to investigate and analyze in determining program objectives

6. Recognize organizational and individual constraints

\section{Establish criteria for determining program priorities}

8. Decide on degree of rigidity/flexibility of planned program

9. Legitimize and obtain support of formal and informal power situations
10. Select and organize learning experiences

11. Identify instructional design with appropriate methods,
techniques, and devices

12. Utilize effective promotional priorities

13. Obtain resources necessary to support the program

14. Determine the effectiveness, results, and impact

15. Communicate program value to appropriate decision makers.

\section{Cervero \& Wilson (1994)}

Cervero and Wilson's Planning Responsibly for Adult Education (1994) proposed a participant-centered model of program planning as a social activity based on responsible planning theory. They assert that effective planning cannot be undertaken without an in-depth understanding of the influence power and divergent interest exert over the particular social context in which the program plan is being developed. Their model focuses on "politics, ethical obligations, power, interests, communication, and language as important contexts for the success of programs" (Franz et al., 2015). Program development here is an inherently social exercise which necessitates constant negotiation with stakeholders. The emphasis on power relations built into the programming requires a high degree of social literacy for educators to responsibly implement the curriculum. Cervero and Wilson (1994) contend educators must be:

\section{Knowledgeable about their respective institution}

2. Politically astute

\section{Skilled in negotiating}

4. Capable of creating and sustaining substantively democratic planning processes

\section{Bennet \& Rockwell (1994)}

The Targeting Outcomes of Programs (TOP) Model was refined in 1994 by Claude Bennett and Kay Rockwell from Bennett's (1975) hierarchy, a foundational model for evaluating program outcomes referenced frequently in Extension. The TOP Model is oriented towards achieving specifically targeted outcomes. Within this model, the program planning and program performance (implementation) sides of the model are mirror images of each other. This inversion of planning and performance distinguishes the TOP Model from other frequently referenced models 
(Harder, 2009). The following conditions are present within both the planning and performance zones of the model:

1. Resources - time, money, human capital (e.g., number of county faculty needed to facilitate program, number of volunteers needed at each activity), in-kind support from external organizations, donations

2. Activities-any educational session, such as a class, workshop, seminar, field day, or consultation

\section{Participation-involvement of learners and volunteers}

4. Reactions-evidence of participant satisfaction and engagement

5.K.A.S.A - an acronym for the knowledge, attitudes, skills, and aspirations of participants

\section{Practices-behaviors of the participants}

7.SEE conditions - social, economic, and environmental conditions, such as family health, community income, or pollution levels

\section{Boone (2002)}

The conceptual programming model developed here represents an expansion of scope and scale of the 1971 Boone, Dolan, \& Shearon model, promoting a systems approach to organizational improvement through the key sub-processes of program facilitation, implementation and evaluation. There is clear emphasis on linking the organizational process to the community it aims to service, as well as understanding organizational renewal and framing the planning process within macro and micro lenses to better monitor and adapt to the changing needs of a public of interest.

\section{Green \& Kreuter (2005)}

The PRECEDE-PROCEED model rests within a framework initially proposed to help health program planners, policy makers, and evaluators assess situations and design health programs efficiently. The model strives to provide a comprehensive framework to adequately assess patient health and quality of life through design, implementation, and evaluation streams of health promotion and other public health programs with an emphasis on participant engagement. In this framework, health behavior is influenced by both individual and environmental conditions, which demarcates the two terms in the title of the model. The educational condition represents PRECEDE, an acronym for Predisposing, Reinforcing and Enabling Constructs in Educational Diagnosis and Evaluation, while the environmental condition-PROCEED, stands for Policy, Regulatory, and Organizational Constructs in Educational and Environmental Development. The model is comprised of eight phases largely predicated on how to guide program planners to work backwards from desired outcomes to determine appropriate strategies.

Table 1 seeks to articulate distinguishing features of the program development models in relation to operational context, client system orientation (who the program is intended to serve), the focus or scope of the program, and the main or guiding themes directing the program model (Boone et al., 2002). It is evident that there may be overlap between the models' placement of these categories; however, this table will still serve to demonstrate salient distinctions between models.

\section{Conclusion}

As you can see, there are several models that exist and can be used by Extension professionals for planning the development and evaluation of their programs. Each model provides specific benefits to the user and outlines a different approach for developing a successful program. The information in this document is intended to provide you with an outline of the models and their benefits, as well as the similarities and differences of each. If you see a model that you believe would be effective for your program, we recommend that you conduct additional research on its applicability to your program either using the resources cited in this document or consulting additional resources on the internet.

\section{References}

Boone, E., Safrit, D., \& Jones, J. (2002). Developing programs in adult education: A conceptual programming model (2 ed.). Long Grove, IL: Waveland Press.

Duttweiler, M. (2006). CCEPDC 101 Program Development [video file]. Retrieved from https://www.youtube. $\mathrm{com} /$ watch? feature=player_detailpage $\& \mathrm{v}=\mathrm{XRLlt1}$ evrG0

Franz, N. K., Garst, B. A., \& Gagnon, R. J. (2015). The Cooperative Extension Program Development Model: Adapting to a Changing Context. Journal of Human Sciences and Extension, 3(2), 3. Retrieved from http://lib.dr.iastate.edu/ cgi/viewcontent.cgi? article $=1009 \&$ context=edu_pubs

Forest, L. B., McKenna, C., \& Donovan, J. (1986). Program Development and Evaluation. In Connections: A" How-To" 
Handbook for Developing Extension Long-Range Plans and Major Programs. Cooperative Extension, University of Wisconsin-Madison.

Green, L., Kreuter, M. (2005). Health program planning: An educational and ecological approach. 4th edition. New York, NY: McGraw-Hill.

Harder, A. M. (2009). Using the TOP Model to Measure Program Performance: A Pocket Reference. WC092. Gainesville: University of Florida Institute of Food and Agricultural Sciences. http://edis.ifas.ufl.edu/wc092

Rockwell, K., \& Bennett, C. (2004). Targeting outcomes of programs: A hierarchy for targeting outcomes and evaluating their achievement. Retrieved from http://digitalcommons.unl.edu/cgi/viewcontent.cgi article $=1047 \&$ context $=\mathrm{a}$ glecfacpub

Seevers, B., \& Graham, D. (2012). Education through Cooperative Extension (3 ed.). Fayetteville, AR: University of Arkansas. 


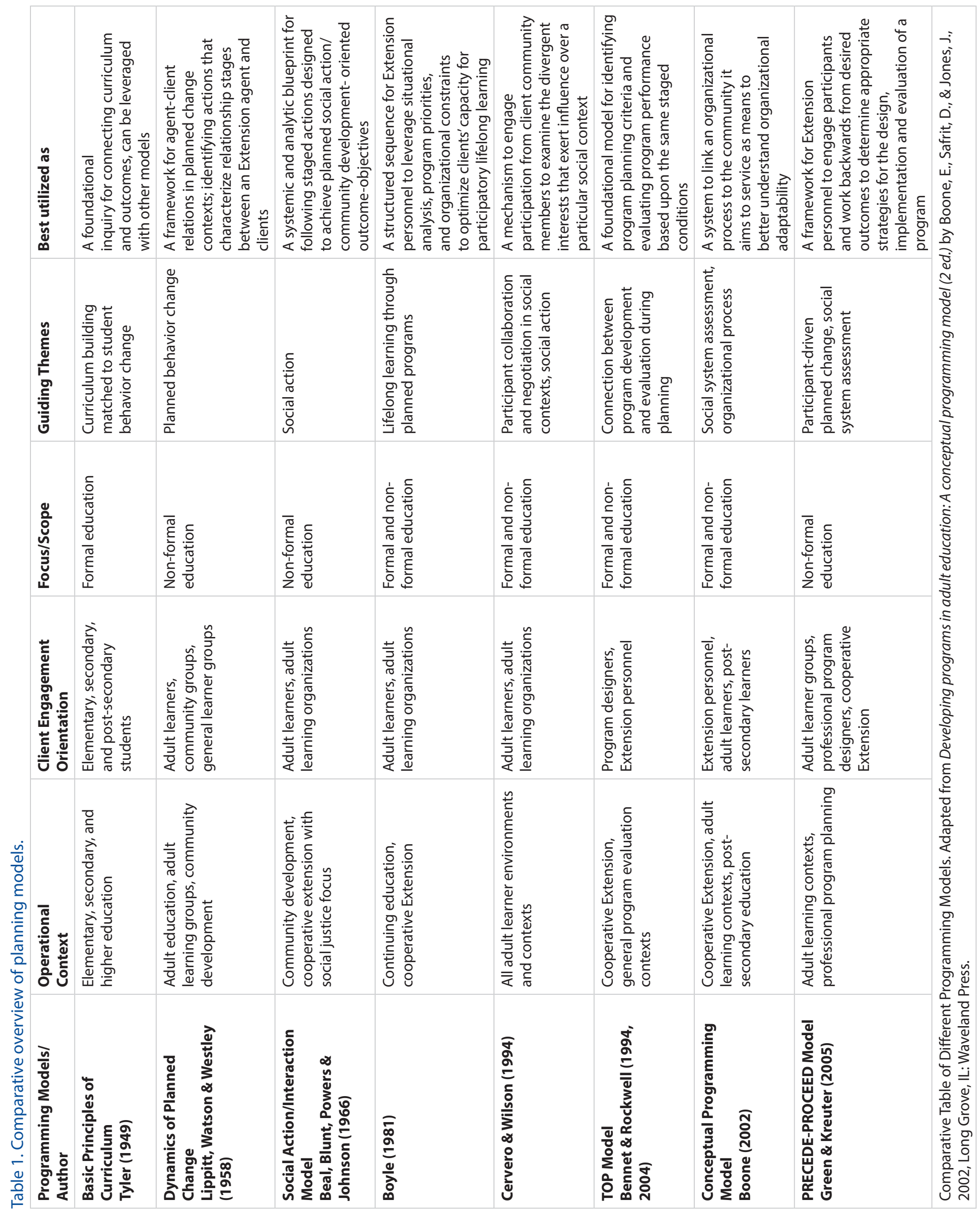

